\title{
Theoretical simulation of the optimal relation between active material, binder and conductive additive for lithium-ion battery cathodes
}

\author{
D. Miranda ${ }^{1}$, A. Gören ${ }^{2,3}$, C. M. Costa ${ }^{2,3^{*}}$, M. M. Silva ${ }^{3}$, A. M. Almeida ${ }^{2}$, \\ S. Lanceros-Méndez $z^{2,4,5}$ \\ 12Ai - Polytechnic Institute of Cávado and Ave, Campus do IPCA, 4750-810 Barcelos, \\ Portugal \\ ${ }^{2}$ Centro de Física, Universidade do Minho, 4710-057 Braga, Portugal \\ ${ }^{3}$ Centro de Química, Universidade do Minho, 4710-057 Braga, Portugal \\ ${ }^{4}$ BCMaterials, Basque Center for Materials, Applications and Nanostructures, \\ UPV/EHU Science Park, 48940 Leioa, Spain \\ ${ }^{5}$ IKERBASQUE, Basque Foundation for Science, 48013 Bilbao, Spain
}

\begin{abstract}
The cathode formulation for lithium-ion batteries has been optimized taking into consideration different active material, polymer binder and conductive additive ratios. Theoretical simulations have been carried out to evaluate the influence of different materials relative contents in the electrode performance, at various discharge rates. Simulations were performed by the finite element method applying the Doyle/Fuller/Newman model for two different active materials $\left(\mathrm{C}-\mathrm{LiFePO}_{4}\right.$ and $\mathrm{LiMn}_{2} \mathrm{O}_{4}$ ) and some results were compared with experimental data.

The optimization of the electrode formulation is dependent on the maximum value of $n$, defined as the ratio polymer binder/conductive additive. The electrical conductivity of the cathode depends on the conductive material, thus it is dependent on the ratio $n$. The optimum balance of the cathode components is reported considering the performance and the mechanical stability.
\end{abstract}

Keywords: LFP; LMO; C-45; binder; cathodes; lithium-ion batteries

\section{Introduction}


The rapid technological development of mobile electrical applications leads to the increasingly important question of how to store electrical energy in a more efficient way [1]. Thus, energy storage is critical in modern society, and the most used are batteries [2], particularly, rechargeable lithium-ion batteries, introduced to the market in 1992 by Sony [3]. Lithium-ion batteries are of increasing importance as power sources as they are lighter, cheaper, show higher energy density, lower self-discharge, no memory effect, prolonged service-life, higher number of charge/discharge cycles, environmental friendliness and higher safety when compared to other battery technologies [4]. There are two main types of batteries, defined as primary and secondary batteries, the latter being rechargeable $[5,6]$.

The main constituents of lithium-ion batteries are the cathode, the anode and the separator membrane [7] and the key issues are to improve specific energy, power, safety and reliability [8]. For the various components of the batteries it is necessary to improve the constituent materials namely the cathode, due to its influence on the battery capacity [9].

Cathodes are typically made with an active material, a polymer binder and a conductive additive. The most used active materials are lithium iron phosphate $\left(\mathrm{LiFePO}_{4}\right)$, lithium nickel manganese cobalt oxide $(\mathrm{LiNiMnCoO})$, lithium cobalt oxide $\left(\mathrm{LiCoO}_{2}\right)$, lithium nickel oxide $\left(\mathrm{LiNiO}_{2}\right)$, lithium nickel cobalt aluminum $\left.(\mathrm{LiNiCoAlO})_{2}\right)$, lithium titanate oxide $\left(\mathrm{LiTiO}_{2}\right)$ and lithium manganese spinel oxide $\left(\mathrm{LiMn}_{2} \mathrm{O}_{4}\right)$, among others [9].

The key characteristics of the active materials include being easily reducible, reacting with lithium in a reversible manner, being a good electronic conductor and stable, i.e. not undergoing structural degradation when charging or discharging the battery [4].

The relevant cathode parameters which affect its performance include the active mass loading, the porosity, the thickness and the ratios between the active material, the binder 
and the conductive additive [10-15]. In this context, more than 40 formulations have been reported for $\mathrm{C}-\mathrm{LiFePO}_{4}$ as an active material, ranging from $60 \%$ to $95 \%$ for the active material, from $2 \%$ to $25 \%$ for the binder and from $3 \%$ to $30 \%$ for the conductive additive [14]. Percolation is achieved for a volume fraction of different active material from $30 \%$ to $10 \%$ [16].

Recently, the influence of inter-particle resistance between active materials with and without conductive carbon were studied, demonstrating the relevance of lithium ionic transfer in the discharge capacity of the battery [17]. Further, the influence of the microscale morphological characteristics of the battery electrode was studied [18-20] and it was observed that the randomness of the particle size distribution also results in a heterogeneous distribution of lithium concentration and electrode potential [19]. Similarly, the morphology of the electrodes affect its macromechanical properties due to the interconnected network of binder and active material particles [20].

Finally, it has been also shown that a multi-layered distribution of porosity along the thickness of the electrode has the potential improve battery performance [21].

Thus, it is clear from the different cathode electrode morphologies and large variations in cathode compositions reported in the literature that it is necessary its optimization, allowing the fabrication of high-quality lithium-ion battery cathodes for applications such as printed batteries [22]. This optimization can be guided by computer simulation of a battery performance, based on the electrochemical reactions describing the physical-chemical properties of the materials to be used as electrodes and separators [23].

This work is devoted to the optimization of the cathode formulation for two active materials $\left(\mathrm{C}-\mathrm{LiFePO}_{4}\right.$ and $\left.\mathrm{LiMn}_{2} \mathrm{O}_{4}\right)$ taking also into account the porosity and the 
electronic conductivity. In this way, the focus of this study is to reach the optimal ratios of the cathode components to obtain higher capacity, for a fixed length of the battery.

\section{Preparation of the cathodes and battery assembly}

To compare with theoretical predictions, several cathodes were prepared and subject to charge-discharge measurements at room temperature for different current densities $(\mathrm{C} / 10$ and $\mathrm{C} / 2)$ in the voltage range from 2.5 to $4.2 \mathrm{~V}$ for LFP and from 3.5 to $4.2 \mathrm{~V}$ for LMO, using a Landt CT2001A Instrument.

C-LiFePO 4 (LFP, Particle size: $\mathrm{D}_{10}=0.2 \mu \mathrm{m}, \mathrm{D}_{50}=0.5 \mu \mathrm{m}$ and $\left.\mathrm{D}_{90}=1.9 \mu \mathrm{m}\right)$, carbon black (Super P-C45), poly(vinylidene fluoride) (PVDF, Solef 5130) and N-methyl-2pyrrolidone (NMP) were acquired from Phostech Lithium, Timcal Graphite \& Carbon, Solvay and Fluka, respectively.

$\mathrm{LiMn}_{2} \mathrm{O}_{4}$ (LMO) was synthesized via sol gel method as indicated in [24]. The cathodes were prepared by mixing LFP or LMO as active materials, Super P, and the polymer binder in NMP solvent with a weight ratio of 80:10:10 (wt.\%).

After complete dissolution of the polymer binder, small amounts of dried mixed solid material (LFP/LMO and Super P) were added to the solution. This mixture was kept under constant stirring $(1000 \mathrm{rpm})$ at room temperature for 3 hours to obtain a good dispersion.

The electrode slurry was then spread onto an aluminum foil and dried in air atmosphere at $80{ }^{\circ} \mathrm{C}$ in a conventional oven (ED 23 Binder). After complete evaporation of the solvent, the cathodes were dried at $90{ }^{\circ} \mathrm{C}$ in vacuum before being transferred into a glove-box.

Two Swagelok type cells were assembled in a home-made argon-filled glove box: metallic lithium ( $8 \mathrm{~mm}$ diameter) was used for the anode; Whatman glass microfiber 
filters (grade GF/A, $10 \mathrm{~mm}$ diameter) were used as separator; $1 \mathrm{M} \mathrm{LiPF}_{6}$ in ethylene carbonate-diethyl carbonate (EC-DEC, 1:1 vol) or in ethylene carbonate-dimethyl carbonate (EC-DMC, 1:1 vol) (Solvionic) was used as electrolyte and the prepared LFP/LMO electrodes were used as cathodes ( $8 \mathrm{~mm}$ diameter).

\section{Theoretical simulation and model parameters}

Lithium half-cell batteries were simulated for the different cathode active materials and different electrolyte solutions. The half-cell battery structure is: [anode, (Li metallic) | separator, $\mathrm{P}(\mathrm{VDF}-\mathrm{TrFE})$ soaked in $1 \mathrm{M} \mathrm{LiPF}_{6}$ in $\mathrm{EC}: \mathrm{DEC}$ or EC:DMC | cathode, (LFP) or (LMO)] and the simulations were carried out by implementing the finite element method for a 2D geometry. For the 2D model, the mass loading is just related with the area of each electrode.

The main equations governing the operation of the different components of the half cell batteries (Table 1) are based on the Doyle/Fuller/Newman model [25-30] and the finite element method calculations were implemented in MATLAB for an ideal cell.

\section{Table 1}

Summary of the main equations governing the different processes and phenomena in the cathode and in the separator/electrolyte for the $\mathrm{Li} / \mathrm{LiFePO}_{4}$ and $\mathrm{Li} / \mathrm{LiMn}_{2} \mathrm{O}_{4}$ half-cells. The nomenclature is indicated in Annex 1.

\begin{tabular}{ccc}
\hline $\begin{array}{c}\text { Electrochemical } \\
\text { Reactions }\end{array}$ & Governing Equation & Region \\
\hline $\begin{array}{c}\text { Solid phase } \\
\text { conduction }\end{array}$ & $-\frac{\sigma_{e f, i}}{\delta^{2}} \frac{\partial^{2} \phi_{E}}{\partial x^{2}}=-F a J_{L i^{+}}$ & Electrode \\
$\begin{array}{c}\text { Electrolyte phase } \\
\text { conduction }\end{array}$ & $-\frac{K_{e f, i}}{\delta^{2}} \frac{\partial^{2} \phi_{L}}{\partial x^{2}}=F a j_{L i^{+}}+\frac{2 k R T}{F}\left(1-t_{+}^{0}\right) \frac{\partial^{2} \ln C_{L}}{\partial x^{2}}$ & $\begin{array}{c}\text { Electrode, } \\
\text { separator }\end{array}$ \\
$\begin{array}{c}\text { Electrolyte phase } \\
\text { diffusion }\end{array}$ & $\varepsilon_{i} \frac{\partial C_{L}}{\partial t}=\frac{D_{e f, i}}{\delta^{2}} \frac{\partial^{2} C_{L}}{\partial x^{2}}+a\left(1-t_{+}^{0}\right)$ & $\begin{array}{c}\text { Electrode, } \\
\text { separator }\end{array}$ \\
$\begin{array}{c}\text { Solid phase } \\
\text { diffusion }\end{array}$ & $\frac{\partial C_{E}}{\partial t}=D_{L i}\left[\frac{\partial^{2} C_{E}}{\partial r^{2}}+\frac{2}{r} \frac{\partial C_{E}}{\partial r}\right]$ & Electrode \\
\hline
\end{tabular}




\begin{tabular}{ccc}
\hline $\begin{array}{c}\text { Activation reaction } \\
\text { (Butler-Volmer } \\
\text { Kinetics) }\end{array}$ & $j_{L i^{+}}=2 k_{i}\left(c_{E, \text { max }, i}-\left.c_{E, i}\right|_{r=R_{i}}\right){ }^{0.5}\left(\left.c_{E, i}\right|_{r=R_{i}}\right)^{0.5} c^{0.5} \sinh \left[\frac{0.5 F}{R T}\left(\varphi_{E}-\varphi_{L}-U_{i}\right)\right]$ & Electrode \\
$\begin{array}{cc}\text { Diffusion/ionic and } \\
\text { electronic } \\
\text { conductivity }\end{array}$ & $D_{e f, i}=D_{l} \varepsilon_{i}^{\text {brugg }}$, brugg $=1.5$ & Electrode, \\
separator \\
$\begin{array}{c}\text { Specific interfacial } \\
\text { area }\end{array}$ & $k_{e f, i}=k_{l} \varepsilon_{i}^{\text {brugg }}$, brugg $=1.5$ & Electrode, \\
& $\sigma_{e f, c}=\sigma_{c}\left(1-\varepsilon_{c}-\varepsilon_{f, c}\right)$ & separator \\
& $a_{c}=\frac{3}{R_{i}}\left(1-\varepsilon_{c}-\varepsilon_{f, c}\right)$ & Electrode \\
\hline
\end{tabular}

$i=c($ cathode), $s$ (separator $)$

The equations shown in Table 1 describe the main processes within the electrodes, including the diffusion and the ionic conductivity of lithium ions in the active material, local current density of the electrodes, the kinetics of the heterogeneous reaction at the electrode/electrolyte interface and the mass transport flux. This model also takes into account the porosity of the electrodes, namely the cathode, which is given by $[12,31]$ :

$$
\varepsilon_{c}=\frac{\left(L-W\left(\frac{C_{1}}{D_{1}}+\frac{C_{2}}{D_{2}}+\frac{C_{3}}{D_{3}}\right)\right)}{L}
$$

where $L$ is the length, $W$ is weight per unit area (as it is a $2 \mathrm{D}$ model), $D_{k}$ is the volumetric mass density and $C_{k}$ is weight percentage of the electrode components, where 1 stands for the active material, 2 for the binder and 3 for the conductive additive.

The actual electronic conductivity of the cathode, $\sigma_{c}$, is reduced from the measured electronic conductivity of the neat conductive additive, $\sigma_{3 \text { Pure }}$, by a term depending on the binder to the conductive additive ratio, regardless of the active material $[12,31]$ :

$$
\log \sigma_{c}=\log \sigma_{3 \text { Pure }}-b\left(\frac{\phi_{2}}{\phi_{3}}\right)
$$


where $b$ is an empiric correction parameter, and $\phi_{2}$ and $\phi_{3}$ are defined as the volume fractions of the binder and the conductive additive, respectively. This equation is also used for the electronic conductivity of carbon black-polymer composites [31].

From the definition of $\phi_{k}$ it can be written

$$
\phi_{k}=\frac{V_{k}}{V_{\text {total }}}=\frac{m_{k}}{D_{k}} \times \frac{1}{V_{\text {total }}}
$$

where $V_{\mathrm{k}}$ is the volume of the component $k$ and $V_{\text {total }}$ is the overall electrode volume.

Thus the ratio $\phi_{2} / \phi_{3}$ is easily formulated as

$$
\phi_{2} / \phi_{3}=\frac{m_{2}}{m_{3}} \times \frac{D_{3}}{D_{2}}
$$

which turns out to be

$$
\phi_{2} / \phi_{3}=\frac{C_{2}}{C_{3}} \times \frac{D_{3}}{D_{2}}
$$

It is the ratio $n=C_{2} / C_{3}$ that can be tuned in order to optimize the battery performance, which is the purpose of this work.

All the parameters used for the simulations of the half cells are indicated in Table 2.

\section{Table 2}

Parameters used for the simulations of the Li/LFP and Li/LMO half-cells.

\begin{tabular}{cccc}
\hline & & Li/LFP and Li/LMO cell & \\
\hline Parameter & Unit & Electrolyte & Cathode (LFP/LMO) \\
\hline$C_{E, i, 0}$ & $\mathrm{~mol} / \mathrm{m}^{3}$ & ---- & $800 / 3900$ \\
$C_{E, i, \max }$ & $\mathrm{mol} / \mathrm{m}^{3}$ & ---- & 22806 \\
$C_{L}$ & $\mathrm{~mol} / \mathrm{m}^{3}$ & 1000 & ---- \\
$r$ & $\mathrm{~m}$ & ---- & $1.7 \times 10^{-6} / 1.5 \times 10^{-6}$ \\
$L_{c}$ & $\mathrm{~m}$ & ---- & $70 \times 10^{-6} / 99 \times 10^{-6}$ \\
\hline
\end{tabular}




\begin{tabular}{|c|c|c|c|}
\hline$L_{s}$ & $\mathrm{~m}$ & $430 \times 10^{-6}$ & ---- \\
\hline$k_{e f, i}$ & $\mathrm{~S} / \mathrm{m}$ & $\left(\right.$ value $\left.^{\mathrm{a})}\right) \times 0.30^{1,5} /\left(\right.$ value $\left.^{\mathrm{b})}\right) \times 0.35^{1,5}$ & $\left(\right.$ value $\left.^{\mathrm{a}) \mathrm{b})}\right) \times \varepsilon_{\mathrm{c}}{ }^{1,5}$ \\
\hline$D_{i}$ & $\mathrm{~m}^{2} / \mathrm{s}$ & $\begin{array}{c}\left(3.0 \times 10^{-10}\right) \times 0.30^{1,5} /\left(7.5 \times 10^{-}\right. \\
11) \times 0.35^{1,5}\end{array}$ & $\left(3.0 \times 10^{-10} / 7.5 \times 10^{-11}\right) \times \varepsilon_{\mathrm{c}}$ \\
\hline$D_{L I}$ & $\mathrm{~m}^{2} / \mathrm{s}$ & --- & $8 \times 10^{-18} / 1 \times 10^{-16}$ \\
\hline$k_{i}$ & $\mathrm{~mol} / \mathrm{s} . \mathrm{m}^{2}$ & ---- & $3 \times 10^{-13} / 2 \times 10^{-11}$ \\
\hline Brugg or $p$ & & 1.5 & 1,5 \\
\hline$\varepsilon_{i}$ & & $0.30 / 0.35$ & $\varepsilon_{\mathrm{c}}$ \\
\hline$\sigma_{i}$ & $\mathrm{~S} / \mathrm{m}$ & ---- & $\sigma_{c}$ \\
\hline$\sigma_{3 \text { Pure }}$ & $\mathrm{S} / \mathrm{m}$ & ---- & $100[32]$ \\
\hline$i_{l C}$ & $\mathrm{~A} / \mathrm{m}^{2}$ & \multicolumn{2}{|l|}{$8.66 / 7.96$} \\
\hline$D_{1}$ & $\mathrm{~g} / \mathrm{m}^{3}$ & ---- & $3.34 \times 10^{6} / 2.93 \times 10^{6}$ \\
\hline$D_{2}$ & $\mathrm{~g} / \mathrm{m}^{3}$ & ---- & $1.765 \times 10^{6}$ \\
\hline$D_{3}$ & $\mathrm{~g} / \mathrm{m}^{3}$ & ---- & $1.9 \times 10^{6}$ \\
\hline$W$ & $\mathrm{~g} / \mathrm{m}^{2}$ & --- & $64.6 / 21.8$ \\
\hline$b$ & & --- & 1 \\
\hline$V_{\text {Totalc }}$ & $\mathrm{m}^{3}$ & ---- & $4.45 \times 10^{-9} / 7.25 \times 10^{-9}$ \\
\hline$m_{\text {Totalc }}$ & $\mathrm{g}$ & --- & $4.11 \times 10^{-3} / 1.6 \times 10^{-3}$ \\
\hline \multicolumn{4}{|c|}{ General parameters } \\
\hline Cut-off voltage & $\mathrm{V}$ & \multicolumn{2}{|l|}{$2.5 / 3.4$} \\
\hline$F$ & $\mathrm{C} / \mathrm{mol}$ & \multicolumn{2}{|l|}{96487} \\
\hline$T$ & K & \multicolumn{2}{|l|}{298.15} \\
\hline$R$ & $\mathrm{~J} / \mathrm{mol} \mathrm{K}$ & \multicolumn{2}{|l|}{8.314} \\
\hline$t_{+}^{0}$ & & \multicolumn{2}{|l|}{0.363} \\
\hline$A_{b a t}$ & $\mathrm{~m}^{2}$ & \multirow{3}{*}{\multicolumn{2}{|c|}{$\begin{array}{c}6.36 \times 10^{-5} / 5.02 \times 10^{-5} \\
\mathrm{LiPF}_{6} \text { in EC-DEC/ LiPF } 6 \text { in EC-DMC } \\
\text { PVDF }\end{array}$}} \\
\hline Electrolyte & & & \\
\hline Inert filler & & & \\
\hline
\end{tabular}

a) Model fits: Ionic condutivity as a function of salt concentration for $\mathrm{LiPF}_{6}$ in $\mathrm{EC}-\mathrm{DEC}$ [27]:

$$
k_{l}=0.0911+1.910 c-1.052 c^{2}+0.1554 c^{3}
$$

b) Model fits: Ionic condutivity as a function of salt concentration for $\mathrm{LiPF}_{6}$ in EC-DMC [33]:

$$
\begin{gathered}
k_{l}=2.905 \times 10^{-4}+2.32702 \times 10^{-2} c-1.82683 \times 10^{-2} c^{2}+5.1708 \times 10^{-3} c^{3}-4.977 \\
\times 10^{-4} c^{4}
\end{gathered}
$$

The nomenclature of the aforementioned equations and tables is indicated in Annex 1.

\section{Results and discussion}

The cathodes prepared with $80 \%$ of active material and $10 \%$ of both conductive additive and binder (80:10:10) were subject to charge-discharge measurements, carried out at room temperature for different current densities $(\mathrm{C} / 2$ and $\mathrm{C} / 10)$ in the voltage range 
from 2.5 to $4.2 \mathrm{~V}$ for LFP and from 3.5 to $4.2 \mathrm{~V}$ for LMO, using a Landt CT2001A Instrument.

For the same cathode composition under the same conditions numerical simulations have shown a good agreement with the experimental results. That has allowed to use the model in further essays with high confidence, like changing the cathode component ratios, using different discharge rates and assessing impedances and current densities at the electrodes.

\subsection{LFP and LMO half-cells: validation of the theoretical model}

The battery assemblies with either each pair of electrodes, Li/LFP or $\mathrm{Li} / \mathrm{LMO}$, were made to discharge and their capacities were assessed at two different discharge rates, $\mathrm{C} / 10$ and $\mathrm{C} / 2$. The results presented in Figure 1 compare the experimental measurements with the numerical simulations for each kind of cathode for both discharge rates.
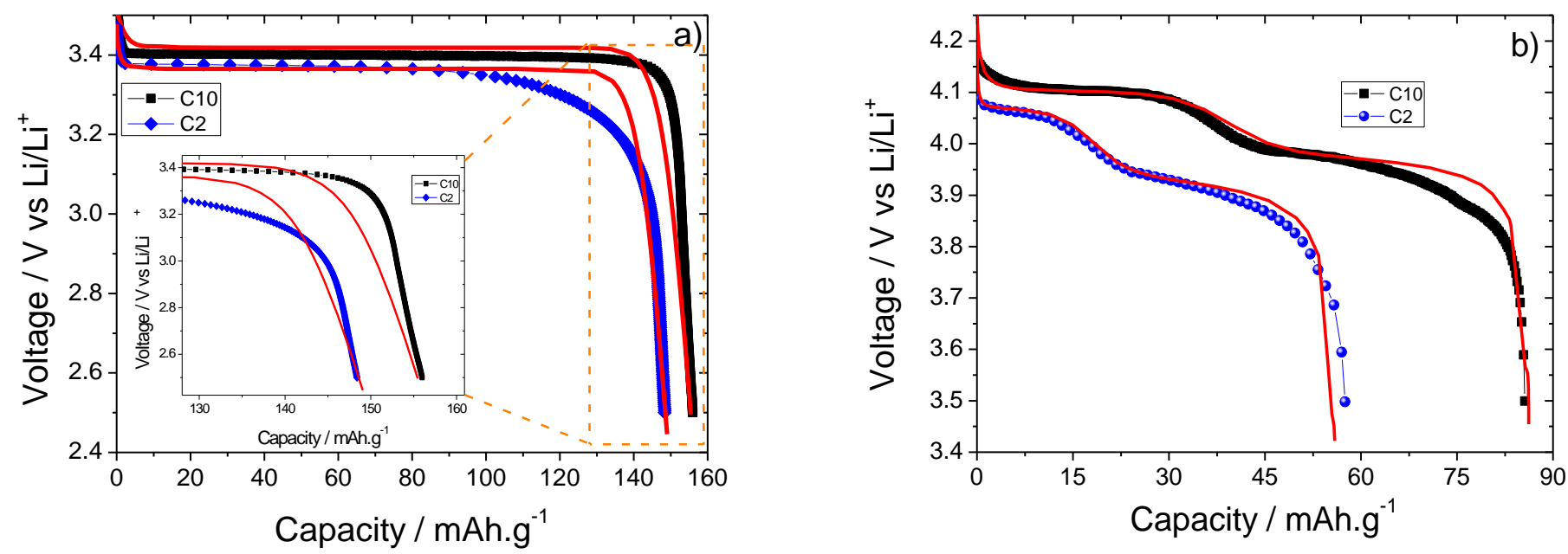

Fig. 1. Voltage as a function of the delivered capacity at $C / 10$ and $C / 2$ discharge rates for the a) Li/LFP and b) Li/LMO half-cells. The solid lines correspond to the numerical simulations, whereas dots and squares are the experimental results. 
For both half-cells and discharge rates, a good agreement is observed between the theoretical and experimental values, which are summarized in Table 3.

\section{Table 3}

Comparison between experimental and simulated battery capacity for two different cathode active materials at two discharge rates.

\begin{tabular}{|c|c|c|c|c|}
\hline & \multicolumn{4}{|c|}{ Capacity (mAh.g ${ }^{-1}$ ) } \\
\hline & \multicolumn{2}{|c|}{$\begin{array}{l}\mathrm{Li} / \mathrm{LFP} \\
\end{array}$} & \multicolumn{2}{|c|}{$\mathrm{Li} / \mathrm{LMO}$} \\
\hline & $\mathrm{C} / 10$ & $\mathrm{C} / 2$ & $\mathrm{C} / 10$ & $\mathrm{C} / 2$ \\
\hline $\begin{array}{l}\text { numerical } \\
\text { simulation }\end{array}$ & 156 & 149 & 86 & 56 \\
\hline experimental & 156 & 148 & 86 & 57 \\
\hline
\end{tabular}

In the higher capacity region of the discharge curves (magnification in Figure 1a) there are small deviations of the theoretical simulations from the experimental results. For all the four cases the discrepancy occurs when the voltage has a steep drop which may be due to differences in the electronic conductivity [34]. Indeed, the theoretical electronic conductivity described by equation (2) does not take into account the microscopic physical-chemical phenomena associated to the electrical resistance of the carbon black particles dispersed within the active material. Further, the voltage difference between theoretical and experimental values is higher for the $\mathrm{C} / 2$ than to the $\mathrm{C} / 10$ discharge rate, which is associated to the internal total resistance effects at high discharge rates [35]. All but these steep parts of the curves show good agreement between the experimental and the simulation results, giving confidence to use the model as a guide for studying cathode formulations without expenditure in time and resources in the laboratory.

\subsection{Influence of the cathode components content in the performance of the half-cell.} The effect of the amount of each cathode component in Li/LFP and Li/LMO half-cells performance was first evaluated by simulating batteries with different active material 
content $\left(\mathrm{C}_{1}\right)$. Then, for each battery with a particular $\mathrm{C}_{1}$, both $\mathrm{C}_{2}$ and $\mathrm{C}_{3}$ were varied in order to obtain discharge curves at a discharge rate of $1 \mathrm{C}$, as shown in Figures $2 \mathrm{a}$ and $\mathrm{b}$ for $\mathrm{Li} / \mathrm{LFP}$ and Figure $3 \mathrm{~b}$ for Li/LMO half-cells, respectively.
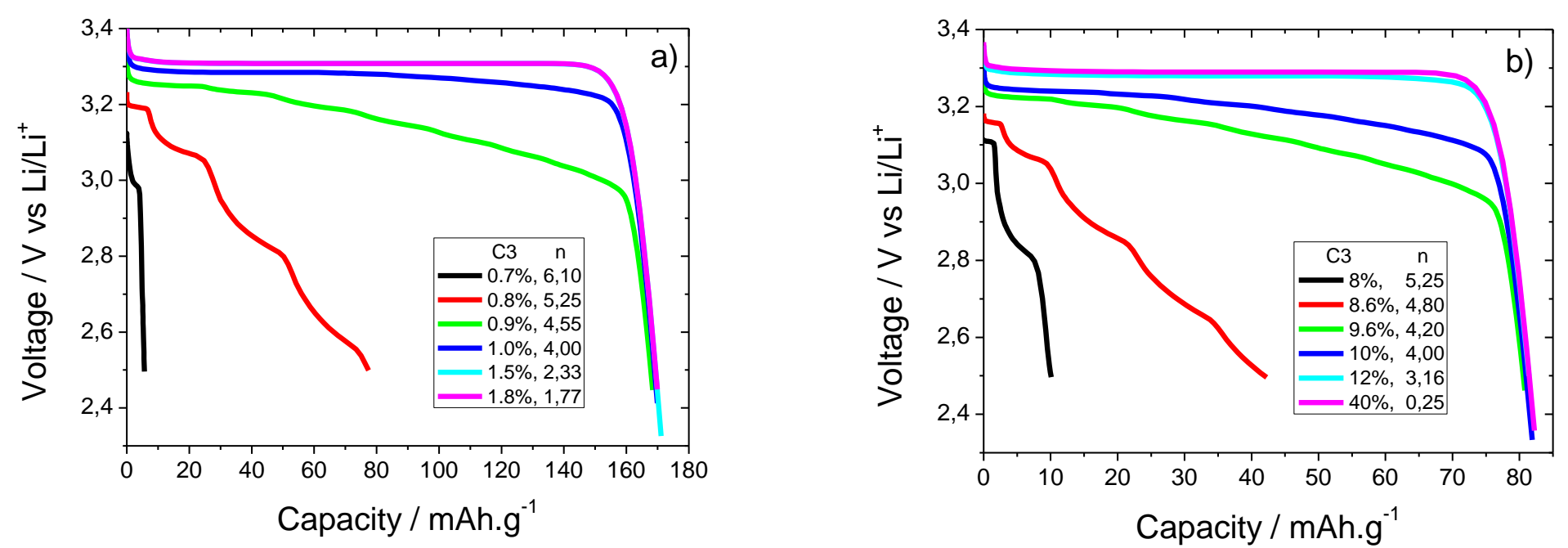

Fig. 2. Voltage as a function of delivered capacity for $\mathrm{Li} / \mathrm{LFP}$ half-cells with $\mathrm{C}_{1}$ : $95 \%$ a) and $50 \% \mathrm{~b})$ at a discharge rate of $1 \mathrm{C}$ and for several $n\left(\mathrm{C}_{2} / \mathrm{C}_{3}\right)$.

Figure 2a) shows a representative Li/LFP half-cell with $95 \%$ of $\mathrm{C}_{1}$ with $\mathrm{C}_{3}$ varying from $0.7 \%$ to $1.8 \% ; \mathrm{C}_{2}$ changes accordingly, thus making the ratio $n$ to span between 6 to 1,8 . It is observed that when $\mathrm{C} 3$ is below $1 \%(n<4)$ there is instability on battery operation and losses in the capacity value, whereas for $\mathrm{C}_{3}$ above $1 \%$ a stable regime of operation is achieved, reaching a maximum close to $170 \mathrm{mAh} \cdot \mathrm{g}^{-1}$.

Figure $2 \mathrm{~b}$ ) shows a similar behaviour for the Li/LFP half-cell with $\mathrm{C}_{1}=50 \%$ and $\mathrm{C}_{3}$ ranging from $8 \%$ to $40 \%$, although the capacity values range from $9.3 \mathrm{mAh}^{-\mathrm{g}^{-1}}$ to only 81.1 mAh.g $\mathrm{g}^{-1}$. The threshold for good battery operation is still $n=4$.

These results show that for a particular content of active material, $\mathrm{C}_{1}$, there is a minimum value of $\mathrm{C}_{3}$ to maintain the battery with low internal resistance (see impedance values later in section 4.3) and without capacity losses. 
It is to notice that lower $C_{1}$ requires higher $C_{3}$ : less active material content determines lower ionic current that should be compensated by higher electronic conduction provided by more conductive additive to maintain a high-performance battery.

The cathode porosity is mostly determined by the active material, due to its higher volumetric mass density compared to that of the binder and the conductive additive. So large variations on the $\mathrm{C}_{3}$ content affect porosity in no more than $\sim 1 \%$.

So it is curial to investigate the maximum ratio of $\mathrm{C}_{2} / \mathrm{C}_{3}$ for any particular value of $\mathrm{C}_{1}$. Ten batteries for each kind of half-cell ( $\mathrm{Li} / \mathrm{LFP}$ and $\mathrm{Li} / \mathrm{LMO})$ with $\mathrm{C}_{1}$ content ranging from $50 \%$ to $95 \%$ were simulated for different ratios $\mathrm{C}_{2} / \mathrm{C}_{3}$ and their capacities were assessed, as it is shown in Figure 3.
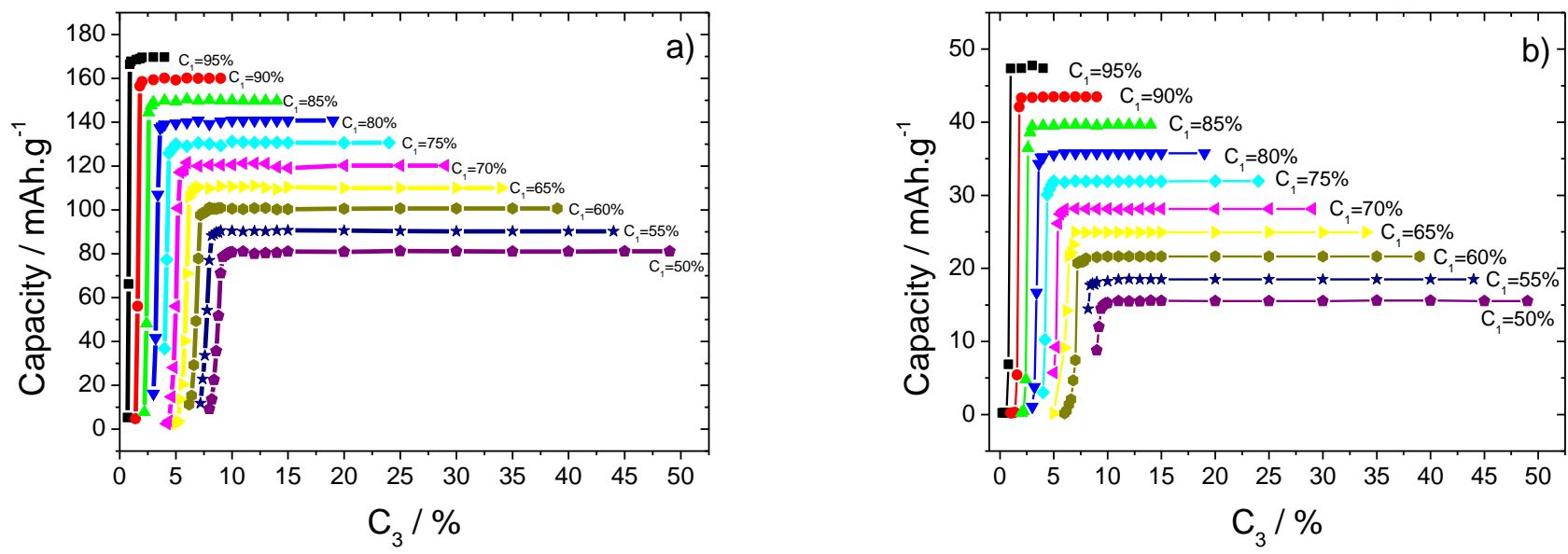

Fig. 3. Delivered capacity as a function of $C_{3}$ for different $C_{1}$ for $L i / L F P$ (a) and $\mathrm{Li} / \mathrm{LMO}(\mathrm{b})$ half-cells at a discharge rate of $1 \mathrm{C}$.

Figures $3 a$ ) and $3 b$ ) show that for batteries with $95 \%$ of $C_{1}$ it is possible to vary $C_{3}$ between $0.7 \%$ and $4 \%$, thus allowing a minimum of $1 \%$ for $\mathrm{C}_{2}$, similar to the minimum of $2 \%$ for $\mathrm{C}_{2}$ content that has been reported experimentally [14].

The two kinds of half-cells show different minima of $\mathrm{C}_{3}$ for the same $\mathrm{C}_{1}$ content in order to obtain the highest capacity values. In both cases, higher conductive material contents increase the electrical conductivity, but do not contribute to an increase of the 
battery capacity, once the amount of active material (associated to the quantity of ions) limits the capacity. The lower content of active material decreases the profitability of ion intercalation, which can be compensated by the addition of conductive material, thus increasing the electrical conductivity favouring the electrons to penetrate deeper into the cathode to neutralize the ions.

Figure 4 shows the minimum percentage of $\mathrm{C}_{3}$ supporting an optimal battery performance for both half-cells with different amounts of $\mathrm{C}_{1}$. The increase in $\mathrm{C}_{3}$ is linear with the decrease in $\mathrm{C}_{1}$ at the same pace for both kinds of active material.

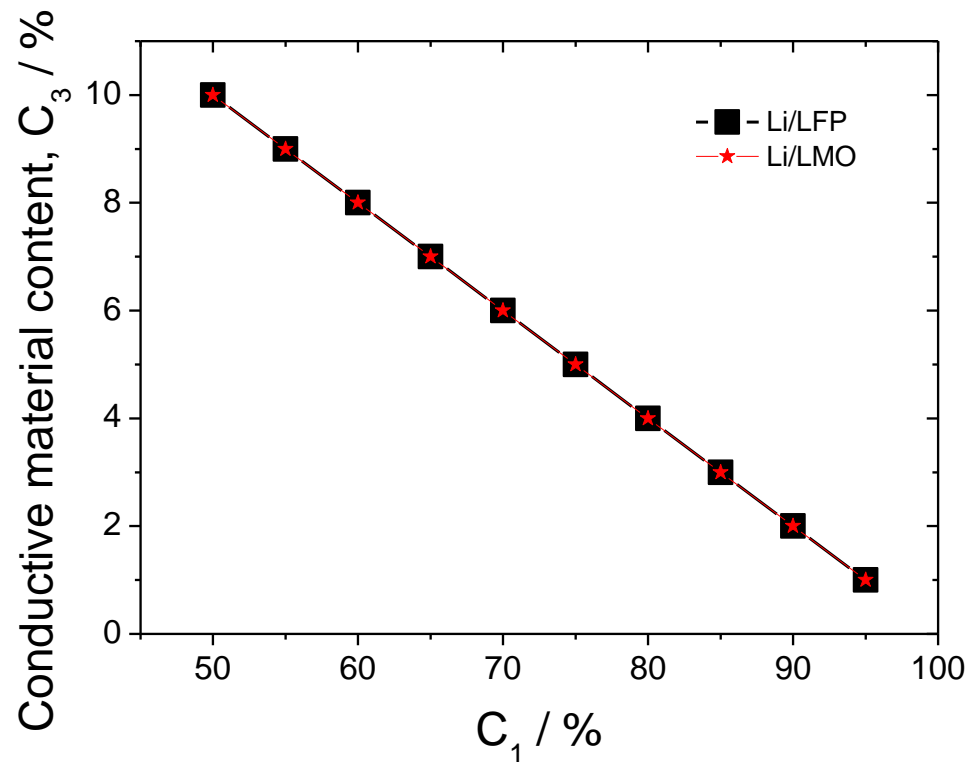

Fig. 4. Minimum percentage of $C_{3}$ as a function of $C_{1}$ for maximum capacity of both half-cells at a discharge rate of $1 \mathrm{C}$.

These results are summarized in Table 4 in which the ratio $n=C_{2} / C_{3}$ is displayed explicitly, leading to the same result in every case: $n=4$.

\section{Table 4}

Maximum values of $n=\mathrm{C}_{2} / \mathrm{C}_{3}$ as a function of $\mathrm{C}_{1}$ for the Li/LFP and Li/LMO half-cells at a discharge rate of $1 \mathrm{C}$.

\begin{tabular}{ccccccccccc}
\hline Half-Cell & & \multicolumn{8}{c}{$\mathrm{C}_{1}$} \\
\hline Li/LFP and Li/LMO & $\mathbf{5 0 \%}$ & $\mathbf{5 5 \%}$ & $\mathbf{6 0 \%}$ & $\mathbf{6 5 \%}$ & $\mathbf{7 0 \%}$ & $\mathbf{7 5 \%}$ & $\mathbf{8 0 \%}$ & $\mathbf{8 5 \%}$ & $\mathbf{9 0 \%}$ & $\mathbf{9 5 \%}$ \\
\hline
\end{tabular}


So, in this study, regardless of the active material considered, and for the same binder and conductive additive, the maximum ratio $n$ is 4 for an optimal half-cell performance, as has been reported experimentally when using carbon black (C-45) as conductive material [14].

The simulated capacity of the half-cell with Li/LFP as active material can be compared to the theoretical value [14] calculated upon the definition based on Faraday's Law [36]:

$$
C_{\text {theo }}=m F /(3600 M)
$$

where $m$ is the number of moles of electrons exchanged per mole of product formed during the electrochemical process, $F$ is the Faraday constant (see Table 2) and $M$ is the molecular weight.

The molecular weight of $\mathrm{LiFePO}_{4}$ is $158 \mathrm{~g} / \mathrm{mol}$ and $m=1$ [14], thus the maximum theoretical capacity of the half-cell Li/LFP is $170 \mathrm{mAh} / \mathrm{g}$, e.g. if the cathode is solely composed of active material.

The functionalization of the cathode demands the use of the other components (binder and conductive material), thus decreasing the effective battery capacity relative to the theoretical value. Accepting as criterion no more than half of the capacity decrease from the ideal value, the amount of active material has to be higher than $50 \%$, as can be seen in Figure 5. 


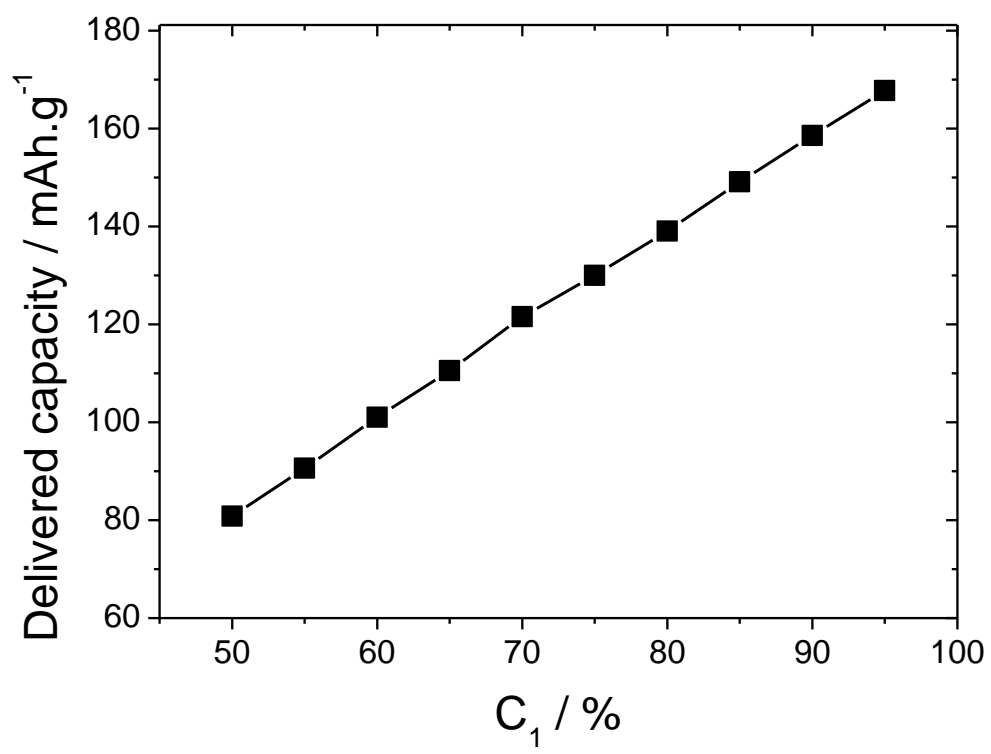

Fig. 5. Delivered capacity as a function of $\mathrm{C}_{1}$ for the Li/LFP half-cell at $1 \mathrm{C}$ discharge rate.

Further, the performance of the half-cell was evaluated at low, medium and high discharges rates: 1C, 5C and 10C (Figure 6).
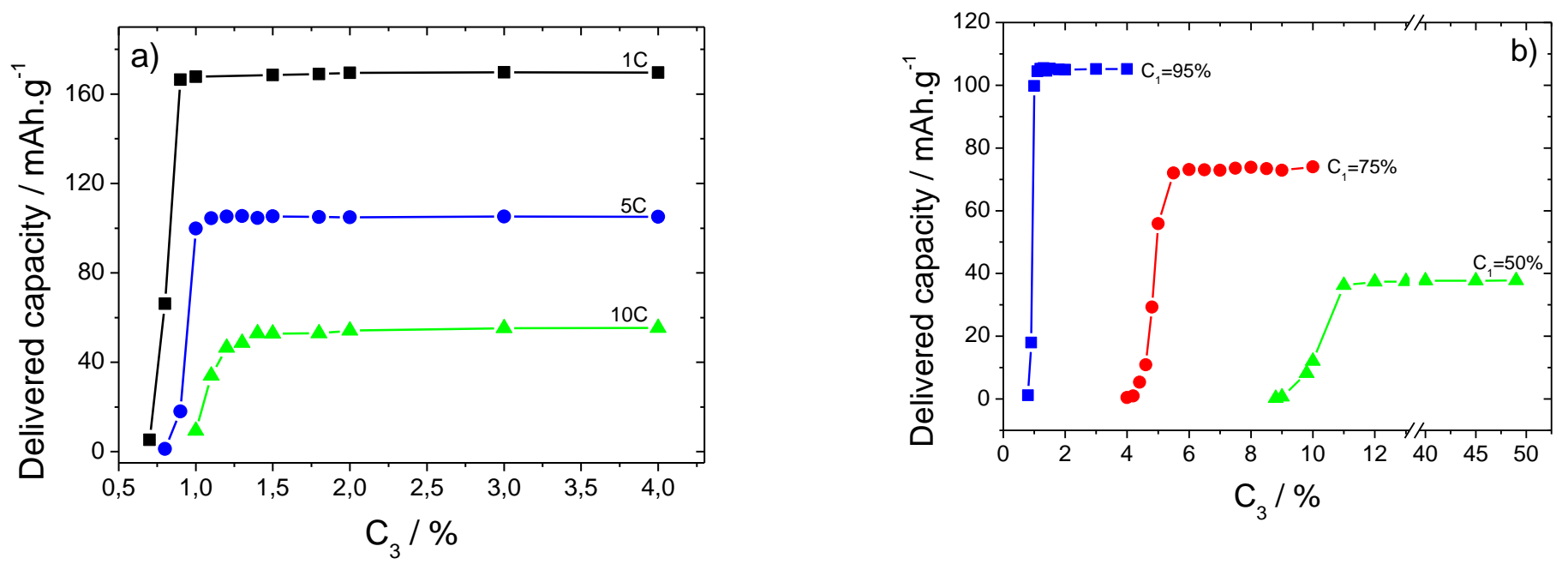

Fig. 6. Delivered capacity as a function of minimum $\mathrm{C}_{3}$ for the Li/LFP half-cells: a) $\mathrm{C}_{1}=95 \%$ at $1 \mathrm{C}, 5 \mathrm{C}$ and $10 \mathrm{C}$ discharge rates and $\left.\mathrm{b}\right) \mathrm{C}_{1}=95 \%, 75 \%$ and $50 \%$ at $5 \mathrm{C}$ discharge rate. 
As mentioned before, to obtain the maximum capacity of a battery with $C_{1}=95 \%$ the minimum $\mathrm{C}_{3}$ is $1 \%$ at $1 \mathrm{C}$. Increasing the discharge rate to $5 \mathrm{C}$ and $10 \mathrm{C}$ requires $\mathrm{C}_{3}$, to be at least $1.1 \%$ and $1.3 \%$, respectively (figure $6 a$ ). Figure $6 \mathrm{~b}$ ) shows that decreasing $\mathrm{C}_{1}$ leads to an increase of the minimum $\mathrm{C}_{3}$.

Table 5 shows these results expressed in terms of $n$ for the Li/LFP half-cells with different $\mathrm{C}_{1}$ at $1 \mathrm{C}, 5 \mathrm{C}$ and $10 \mathrm{C}$ discharge rates.

\section{Table 5}

Maximum values of the $n$ ratio for different $C_{1}$ for Li/LFP half-cells at $1 \mathrm{C}, 5 \mathrm{C}$ and $10 \mathrm{C}$ discharge rates.

\begin{tabular}{cccc}
\hline & \multicolumn{3}{c}{$\mathbf{C}_{\mathbf{1}}$} \\
\cline { 2 - 4 } Discharge Rate & $\mathbf{9 5 \%}$ & $\mathbf{7 5 \%}$ & $\mathbf{5 0 \%}$ \\
\cline { 2 - 4 } 1C & $\mathrm{n}=(4 / 1)=4$ & $\mathrm{n}=(20 / 5)=4$ & $\mathrm{n}=(40 / 10)=4$ \\
$\mathbf{5 C}$ & $\mathrm{n}=(3.9 / 1.1)=3.54$ & $\mathrm{n}=(19.5 / 5.5)=3.54$ & $\mathrm{n}=(39 / 11)=3.54$ \\
$\mathbf{1 0 C}$ & $\mathrm{n}=(3.7 / 1.3)=2.64$ & $\mathrm{n}=(18.5 / 6.5)=2.86$ & $\mathrm{n}=(37 / 13)=2.84$ \\
\hline
\end{tabular}

From Table 5 it can be seen the ratio $n$ is independent of the active material content but decreases for higher discharge rates, requiring higher amounts of $\mathrm{C} 3$ in order to facilitate the reduction of $\mathrm{Li}$ ions by increasing the cathode electronic conduction.

So, it is important to take into account the maximum value of $n$ tailored to the battery intended use, namely regarding the expected discharge rate. 
The impedance of the half-cells was assessed through the Nyquist plots to better understand the conduction phenomena related to the balance of the different cathode components. These tests were carried out at a discharge rate of $1 \mathrm{C}$ and the minimum $\mathrm{C}_{3}$, hence the maximum $n$, was evaluated for different amounts of either Li/LFP or Li/LMO as active materials and the results are shown in Figure 7.

The Nyquist plots are characterized by a semicircle at high frequencies (the overall resistance) and an approximately $45^{\circ}$ line in the low-frequency range, which can be considered as the Warburg impedance, associated to the lithium-ion diffusion in the bulk of the active material [37].

The total impedance corresponds to the sum of the electrolyte resistance $\left(\mathrm{R}_{\mathrm{e}}\right.$, high frequency intercept with the $Z^{\prime}$-axis), the surface film resistance $\left(\mathrm{R}_{\mathrm{f}}, \mathrm{Li}\right.$-ion migration resistance through the solid electrolyte interface (SEI) film formed on the cathode surface) and the charge-transfer reaction resistance $\left(\mathrm{R}_{\mathrm{ct}}\right)$ ascribed to the lithiumintercalation process.
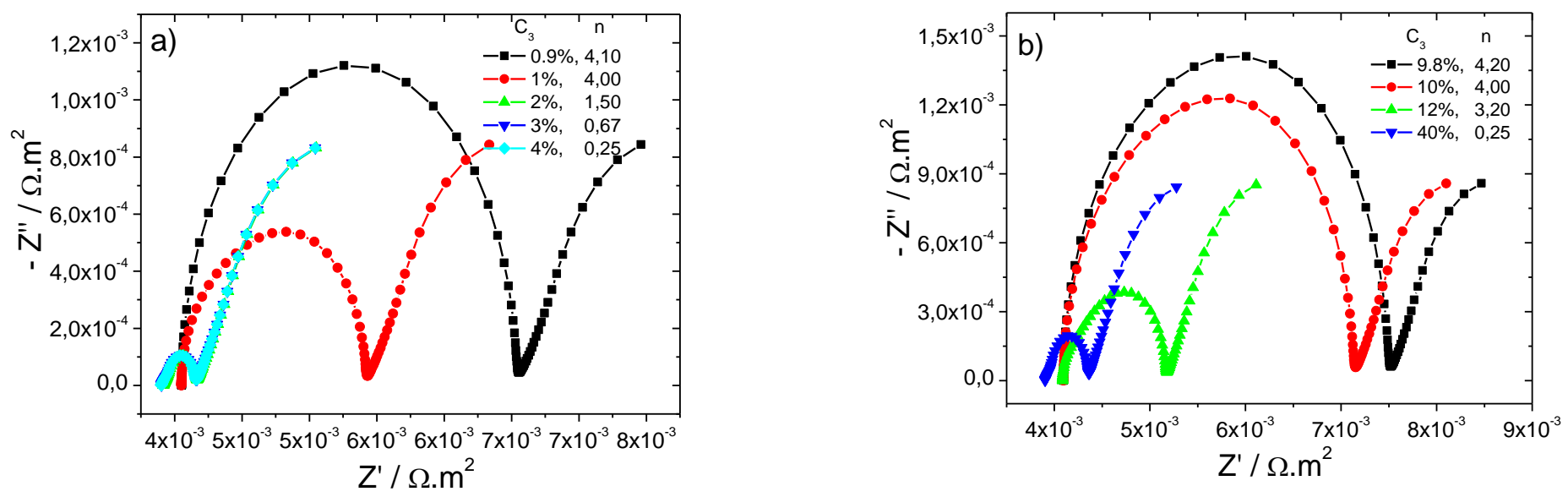


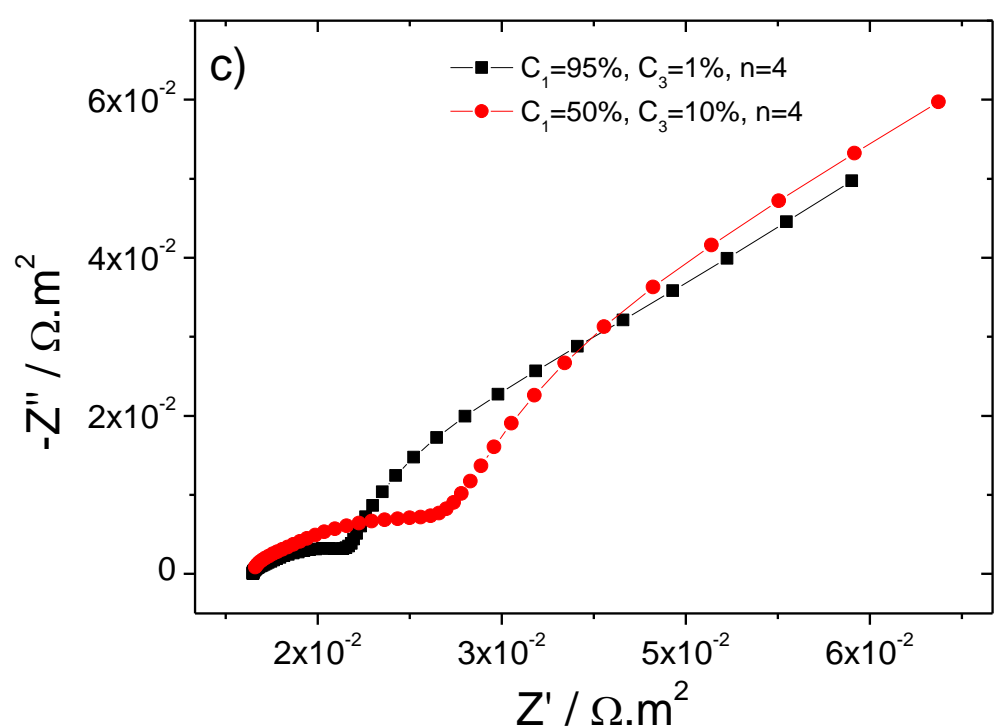

Fig. 7. Nyquist plot for the Li/LFP half-cell: a) $C_{1}=95 \%$ with different $C_{3}$ values at $1 \mathrm{C}$ discharge rate and b) $\mathrm{C}_{1}=50 \%$ with different $\mathrm{C}_{3}$ values at $1 \mathrm{C}$ discharge rate. Nyquist plot for Li/LMO half-cells: c) $\mathrm{C}_{1}=95 \%$ and $50 \%$ and $\mathrm{C}_{3}=1 \%$ and $10 \%$ at $1 \mathrm{C}$ discharge rate.

For the active material LFP, with $\mathrm{C}_{1}=95 \%$, Figure 7 a) shows a decrease in the impedance for $\mathrm{C}_{3}>1 \%(n<4)$, which is consistent with the minimum $\mathrm{C}_{3}$ needed to sustain high performance and stability of the battery operation under a regular discharge rate. Lower content of $\mathrm{C}_{3}$ increases the battery resistance, which affects the intercalation process resulting in a lower battery capacity. The same trend is observed for the Li/LFP half-cell with $\mathrm{C}_{1}=50 \%$ (Figure $7 \mathrm{~b}$ ), but the threshold of $\mathrm{C}_{3}$ is $10 \%$, which still corresponds to $n=4$.

As to the Li/LMO half-cell, Figure 7c) shows that this material exhibits much higher resistance relative to $\mathrm{Li} / \mathrm{LFP}$ with similar content formulations.

This comparison can be extended further as Figure 8 shows the overall impedance values for the $\mathrm{Li} / \mathrm{LFP}$ and $\mathrm{Li} / \mathrm{LMO}$ half-cells with $\mathrm{C}_{1}$ ranging from $50 \%$ to $95 \%$ and the respective minimum $\mathrm{C}_{3}$. 

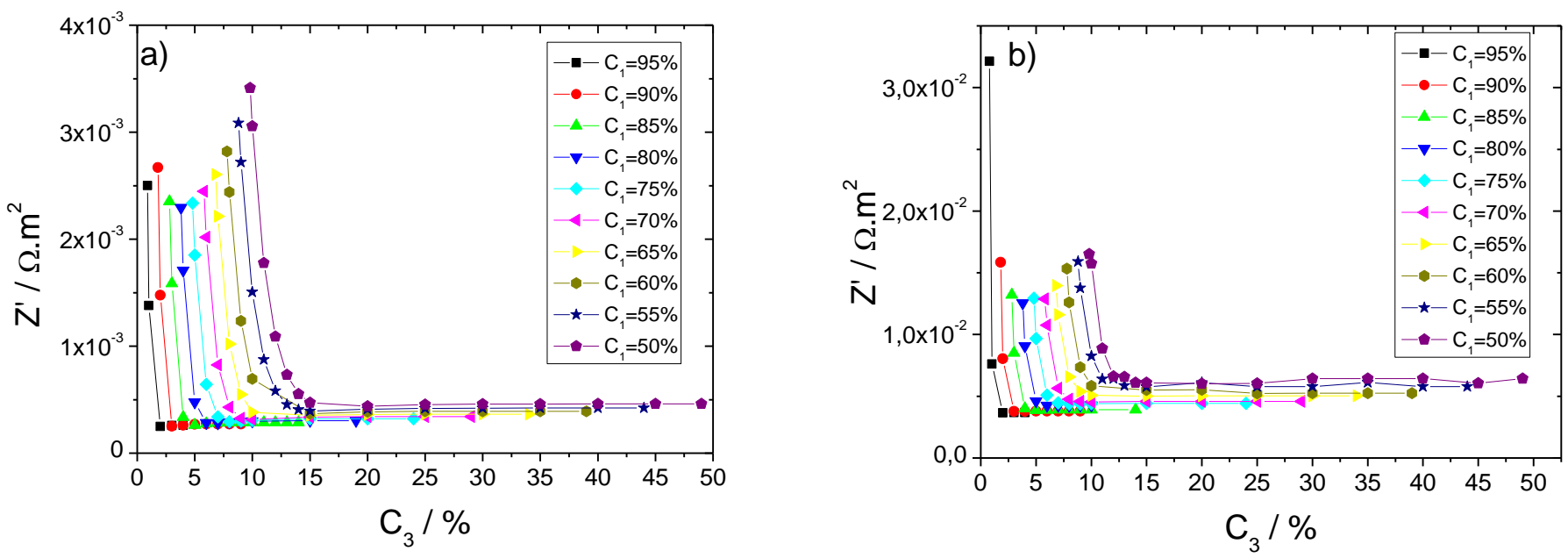

Fig. 8. Total impedance as a function of minimum $C_{3}$ for different $C_{1}$ at $1 C$ discharge rate for: a) Li/LFP and b) Li/LMO half-cells.

For either active material, the lowest impedance values for every $\mathrm{C}_{1}$ is achieved for a $\mathrm{C}_{3}$ that systematically leads to the ratio $n=4$.

\subsection{Ionic and electronic current densities at the cathode}

It is important to evaluate the cathode current densities to investigate the behaviour of ions and electrons during the intercalation process. The ionic current density is defined as the current density of charges associated to lithium ions in the electrolyte within the pores of the cathode. The electronic current density is the current density of the charges associated to electrons moving in the cathode solid phase.

During the discharge process, ions move from the separator towards the current collector, through the pores of the cathode. At the same time, electrons move in the opposite direction, from the current collector to the separator, through the solid phase of the cathode (active and conductive materials). Figure 9 shows a schematic representation of these bipolar charge flows and the intercalation process (the reduction of lithium ions) within the cathode during the discharge process. The boundary between 
the separator and the cathode is located at $\mathrm{x}=0 \mu \mathrm{m}$ and the interface between the cathode and the current collector is located at $\mathrm{x}=70 \mu \mathrm{m}$.

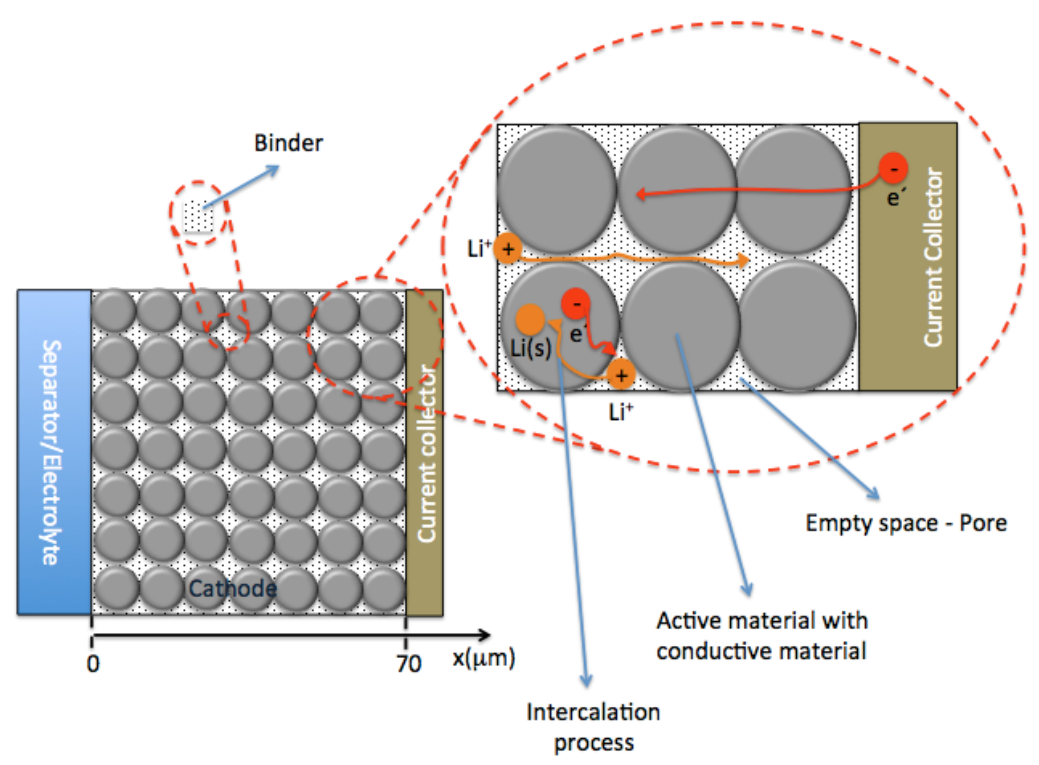

Fig. 9. Schematic representation of a battery cathode, the bipolar charge flows and the intercalation process during the discharge operation.

For the evaluation of the electrode current densities it was chosen the particular instant of time $500 \mathrm{~s}$, as it is within the discharging time range for all batteries assessed.

Figure 10 shows both the ionic and the electronic current densities along the length of the cathode after $500 \mathrm{~s}$ for a Li/LFP half-cell with $95 \%$ of active material and $4 \%$ of conductive material, at $1 \mathrm{C}$ discharge rate. 


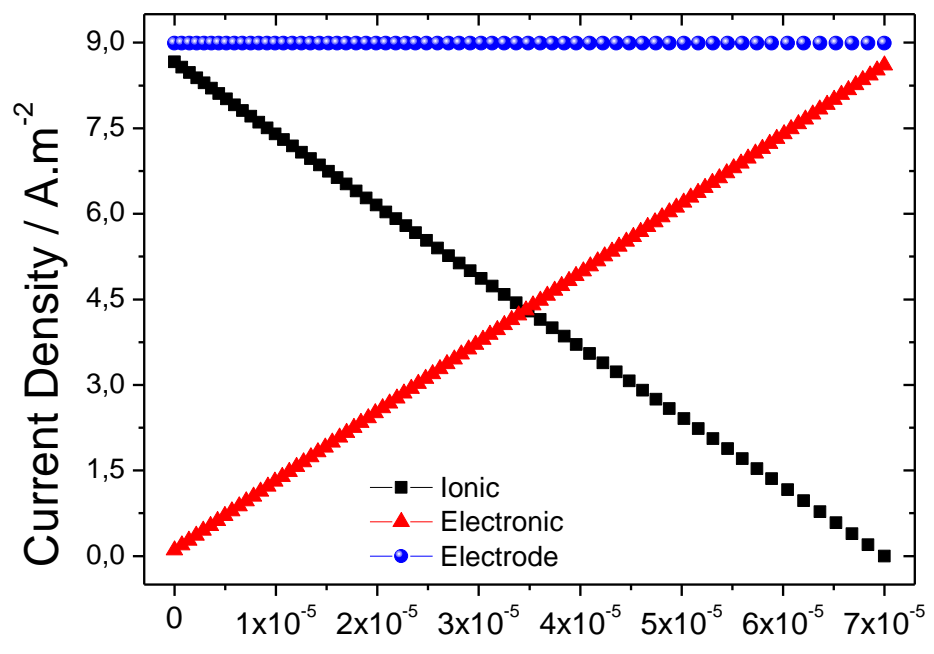

Cathode length / $\mathrm{m}$

Fig. 10. Ionic and electronic current densities along the cathode length for a $\mathrm{Li} / \mathrm{LFP}$ half-cell with $\mathrm{C}_{1}=95 \%$ and $\mathrm{C}_{3}=4 \%$ at $1 \mathrm{C}$ discharge rate, after $500 \mathrm{~s}$. The blue dots correspond to the sum of both current densities along the length of the cathode, showing that the divergence of the total electric charge is null.

The ionic current density decreases linearly from the separator $(x=0 \mu m)$ to the collector $(x=70 \mu \mathrm{m})$, showing that the amount of available lithium ions decreases along the length of the cathode due to the intercalation process, by which ions are neutralized or reduced. Thus, the electronic current density decreases from the collector to the separator. The principle of conservation of electric charge is obeyed, as the sum of both current densities, which make the electrode current density, is constant over the entire length of the cathode.

The results presented for the $\mathrm{Li} / \mathrm{LFP}$ half-cells are also representative of the $\mathrm{Li} / \mathrm{LMO}$ half-cell.

For other $\mathrm{Li} / \mathrm{LFP}$ cathode formulations with $\mathrm{C}_{1}=95 \%$ and $\mathrm{C}_{1}=50 \%$, combined with different amounts of $\mathrm{C}_{3}$, after $500 \mathrm{~s}$ of discharge, the ionic and the electronic current densities are presented in Figures 11 and 12, respectively. Not surprisingly, as in the 
figure before, the ionic and the electronic current densities are mirrored corresponding to a constant electrode density current in every case.
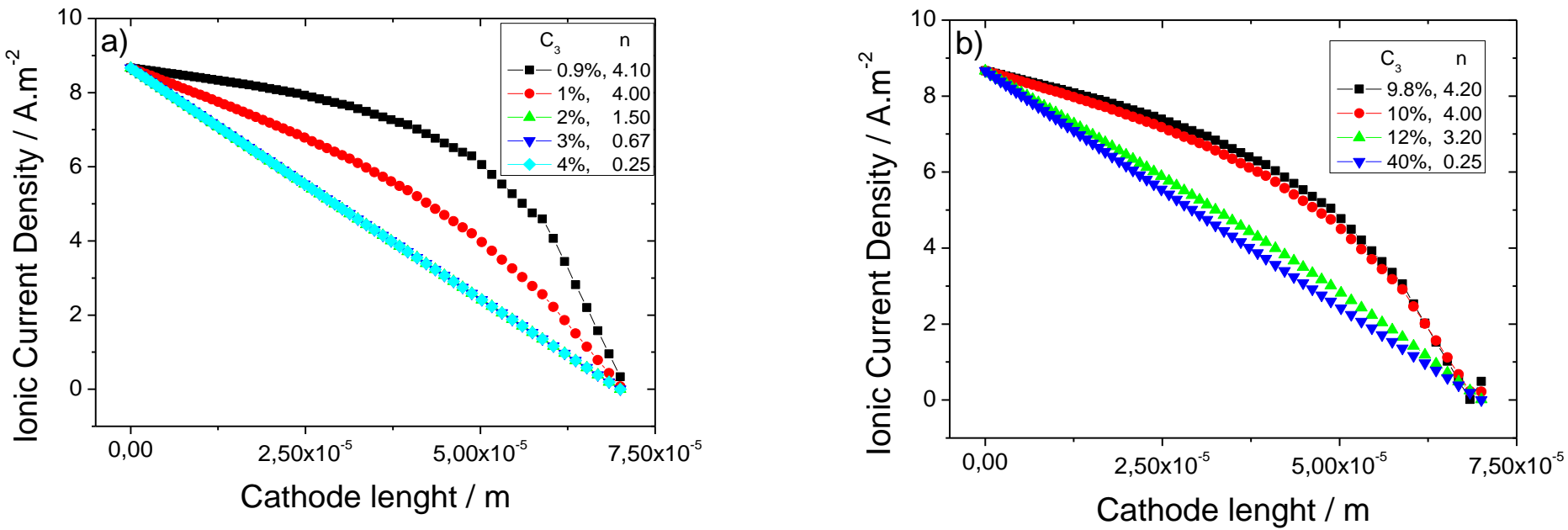

Fig. 11. Ionic current density along the cathode length for Li/LFP half-cell for various $\mathrm{C}_{3}$ at $1 \mathrm{C}$ discharge rate, after $500 \mathrm{~s}$, for $\mathrm{C}_{1}=95 \%$ (a) and $50 \%$ (b).
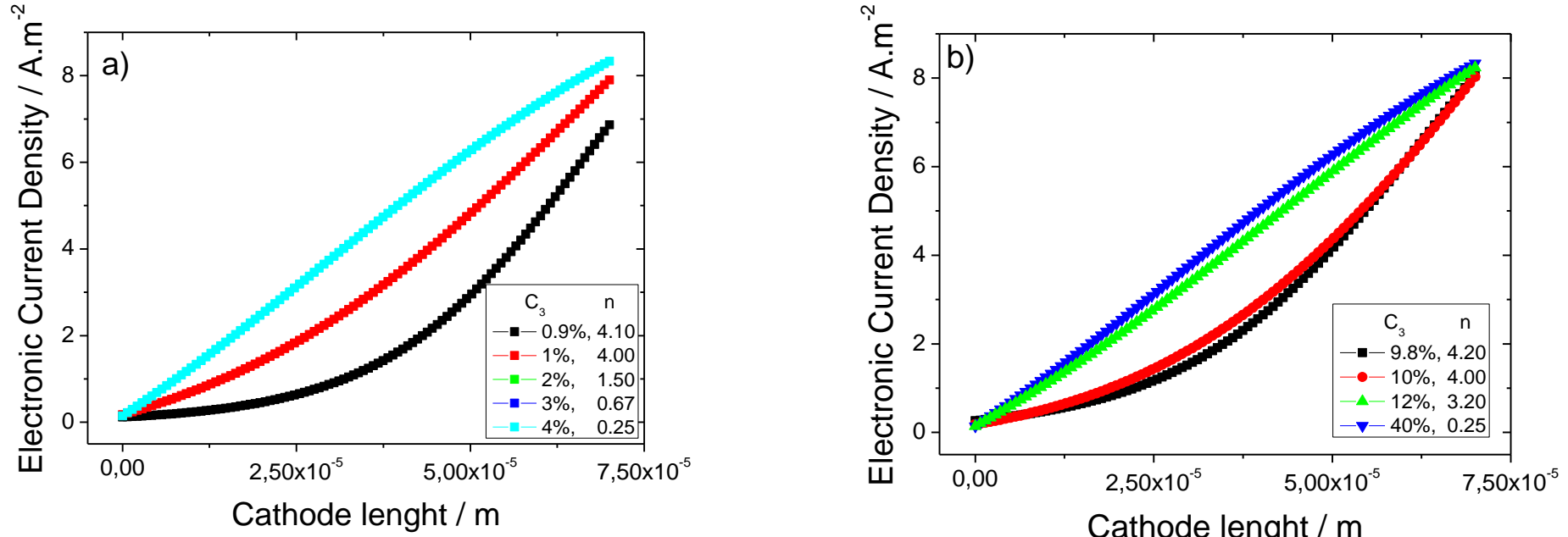

Fig. 12. Electronic current density along the cathode length for Li/LFP half-cell for various $\mathrm{C}_{3}$ at $1 \mathrm{C}$ discharge rate, after $500 \mathrm{~s}$, for $\mathrm{C}_{1}=95 \%$ (a) and $50 \%$ (b).

For the cathodes with $\mathrm{C}_{1}=95 \%$, the linear decrease of the ionic current density occurs for $\mathrm{C}_{3}>1 \%$, corresponding to $n<4$. For $\mathrm{C} 3 \leq 1 \%$ (which means $n \geq 4$ ) the curves in the graphic of Figure 11 a) indicate a deeper penetration of the ions in the cathode before 
intercalation, to which corresponds lower electronic current densities, as can be seen from Figure 12 a). The lower content of conductive additive, which means higher electrical resistance within the solid phase of the cathode, inhibits electrons from going deep in the cathode, thus the intercalations tend to occur closer to the collector.

The same trend is noticed for the cathode formulation with $\mathrm{C}_{1}=50 \%$, and the ratio $n \geq$ 4 still stands for the linear variation of the ionic and the electronic current densities along the cathode (Figures $11 \mathrm{~b}$ and $12 \mathrm{~b}$ ).

For a particular position inside the cathode the evaluation of both current densities can provide some insight on how the charges behave and how the intercalation process progresses over time.

Figure 13 shows the ionic and the electronic current densities as a function of time at $\mathrm{x}$ $=20 \mu \mathrm{m}$ from the cathode/separator interface. The cathode is $70 \mu \mathrm{m}$ long, contains $\mathrm{C}_{1}=$ $95 \%$ and $\mathrm{C}_{3}=0.9 \%$ and the discharge rate is $1 \mathrm{C}$, which corresponds to the black square data in Figures 11 a and 12 a $(n=4.5)$. This is a low content of $\mathrm{C}_{3}$ making the cathode to have a large ohmic resistance.

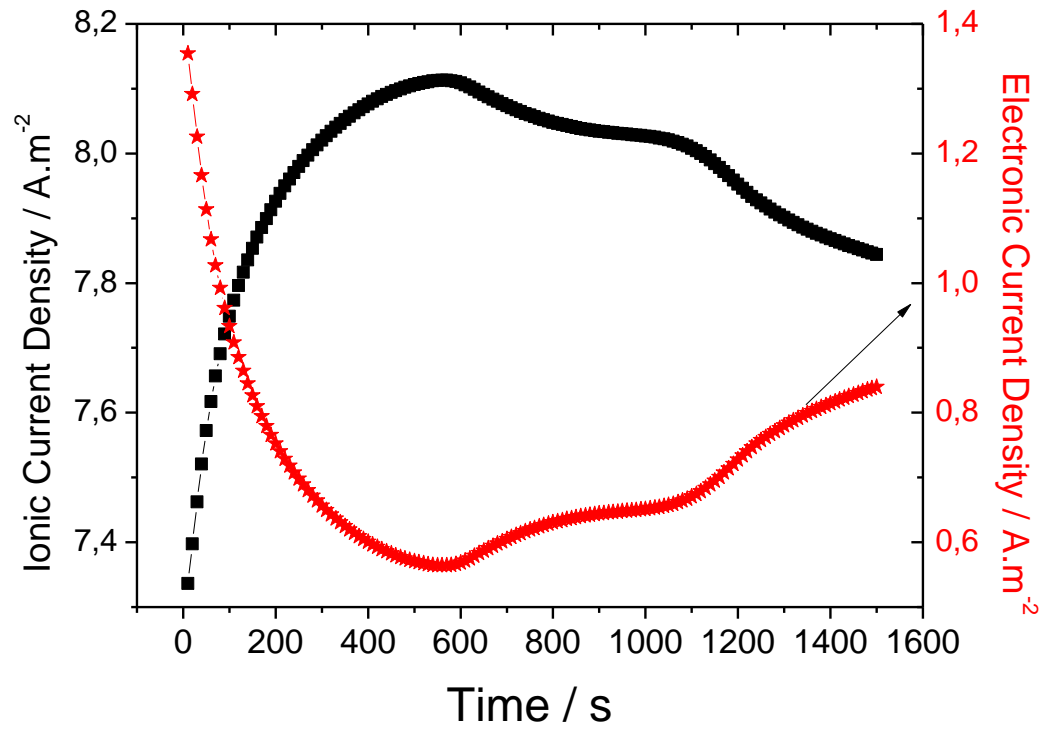


Fig. 13. Ionic and electronic current densities as a function of time for a Li/LFP halfcell with $\mathrm{C}_{1}=95 \%$ and $\mathrm{C}_{3}=0.9 \%$, at $20 \mu \mathrm{m}$ from the separator/cathode interface. The length of the cathode is $70 \mu \mathrm{m}$ and the discharge rate is $1 \mathrm{C}$.

For the time interval shown in Figure 13, the electrode density current is constant, although the ionic current density increases for the first $600 \mathrm{~s}$ and decreases afterwards, whilst the electronic density current has the opposite behaviour.

At the beginning no ions are available at this particular cathode position, as they will come from the separator entering the liquid phase of the cathode. The electronic current is provided by the electrons flowing through the conductive additive towards the separator. The fast growing of the ionic current density together with the fast decrease of the electronic density current indicates that intercalations have started to occur, namely for $\mathrm{x}>20 \mu \mathrm{m}$. As more ions are penetrating deeper in the electrode fewer electrons will get closer to the separator, for the first $600 \mathrm{~s}$. Then the ionic current density turns down, due to the continuous reduction of available pores where the ions have intercalated from the collector to the separator. The ion percolation is shallower making the electrons go further to complete the intercalations. 


\section{Conclusions}

The optimization of the electrode formulation based on different contents of active material, binder and conductive additive is essential for maximizing the electrode properties in lithium-ion batteries. Thus, this work reports on the optimization of the electrode formulation for two active materials: C-LiFePO 4 (LFP) and $\mathrm{LiMn}_{2} \mathrm{O}_{4}$ (LMO). Battery assemblies were made to discharge at two different discharge rates, $\mathrm{C} / 10$ and $\mathrm{C} / 2$, and the measured capacities show a good agreement with the theoretical predictions from the Doyle/Fuller/Newman chemistry model.

It was demonstrated that the ratio $n=\mathrm{C}_{2} / \mathrm{C}_{3}<4$ should be attended in order to achieve the best battery performances. The numerical simulations also yield $n=4$ as the threshold above which, regardless of the active material, the battery exhibits high capacity and low internal resistance, allowing intercalation to occur farthest from the cathode collector, for low and regular discharge rates. Finally, it is concluded that depending on the future use of a particular type of battery, for higher discharge rates the ratio $n$ should be lowered.

Thus, theoretical simulations and experimental evidence allow to recommend that the best composition of the electrode should be $90 \%$ of active material $\left(\mathrm{C}_{1}\right)$ in order to obtain good cycling, and that,, once assuring mechanical stability, $\mathrm{C}_{2}$ and $\mathrm{C}_{3}$ should vary between $2 \%$ and $8 \%$ according to the expected scan rate.

\section{Acknowledgements}

This work was supported by the Portuguese Foundation for Science and Technology (FCT) in the framework of the Strategic Funding UID/FIS/04650/2013. The authors thank FEDER funds through the COMPETE 2020 Programme and National Funds 
through FCT under the projects PTDC/CTM-ENE/5387/2014, UID/CTM/50025/2013

and PTDC/FIS-MAC/28157/2017 and grants SFRH/BD/90313/2012 (A.G.) and SFRH/BPD/112547/2015 (C.M.C.).

Financial support from the Basque Government Industry Department under the ELKARTEK and HAZITEK programs is also acknowledged.

\section{Nomenclature}

\begin{tabular}{|c|c|}
\hline \multicolumn{2}{|c|}{ List of symbols } \\
\hline $\mathrm{a}$ & specific interfacial area, $\mathrm{m}^{2} / \mathrm{m}^{3}$ \\
\hline $\mathrm{C}_{\mathrm{L}}$ & concentration of $\mathrm{Li}$ ions in the electrolyte, $\mathrm{mol} / \mathrm{m}^{3}$ \\
\hline $\mathrm{C}_{\mathrm{E}}$ & concentration of $\mathrm{Li}$ ions in the electrode, $\mathrm{mol} / \mathrm{m}^{3}$ \\
\hline $\mathrm{D}$ & diffusion coefficient of the salt in the electrolyte, $\mathrm{m}^{2} / \mathrm{s}$ \\
\hline $\mathrm{D}_{\mathrm{LI}}$ & diffusion coefficient of $\mathrm{Li}$ ions in the electrode, $\mathrm{m}^{2} / \mathrm{s}$ \\
\hline $\mathrm{k}_{\mathrm{i}}$ & reaction rate constant, $\mathrm{mol} / \mathrm{s} \cdot \mathrm{m}^{2}$ \\
\hline $\mathrm{F}$ & Faraday's constant, $96487 \mathrm{C} / \mathrm{mol}$ \\
\hline$f_{ \pm}$ & activity of the salt in the electrolyte, $\mathrm{mol} / \mathrm{m}^{3}$ \\
\hline $\mathbf{i}_{\mathrm{E}}$ & current density in the electrode, $\mathrm{A} / \mathrm{m}^{2}$ \\
\hline $\mathbf{i}_{\mathrm{L}}$ & current density in the electrolyte phase, $\mathrm{A} / \mathrm{m}^{2}$ \\
\hline $\mathrm{I}_{\text {TOTAL }}$ & total current density, $\mathrm{A} / \mathrm{m}^{2}$ \\
\hline $\mathrm{j}_{\mathrm{Li}}^{+}$ & pore wall flux of $\mathrm{Li}$ ions, $\mathrm{mol} / \mathrm{cm}^{2} \mathrm{~s}$ \\
\hline $\mathrm{L}_{\mathrm{i}}$ & thickness of the component $i(i=\mathrm{a}, \mathrm{s}, \mathrm{c}), \mathrm{m}$ \\
\hline $\mathrm{C}_{1}$ & percentage of the active material, $\%$. \\
\hline $\mathrm{C}_{2}$ & percentage of the binder, $\%$ \\
\hline $\mathrm{C}_{3}$ & percentage of carbon black (C-45). \\
\hline $\mathrm{D}_{1}$ & density of the active material, $\mathrm{g} / \mathrm{m}^{3}$. \\
\hline $\mathrm{D}_{2}$ & density of the binder, $\mathrm{g} / \mathrm{m}^{3}$. \\
\hline $\mathrm{D}_{3}$ & density of carbon black (C-45), $\mathrm{g} / \mathrm{m}^{3}$. \\
\hline $\mathrm{W}$ & weight of the sample per area, $\mathrm{g} / \mathrm{m}^{2}$ \\
\hline$\phi_{\mathrm{i}}$ & volume fraction of the material $\mathrm{i}(\mathrm{i}=1,2,3)$ \\
\hline$V_{\text {Totalc }}$ & total volume of cathode, $\mathrm{m}^{2}$ \\
\hline
\end{tabular}




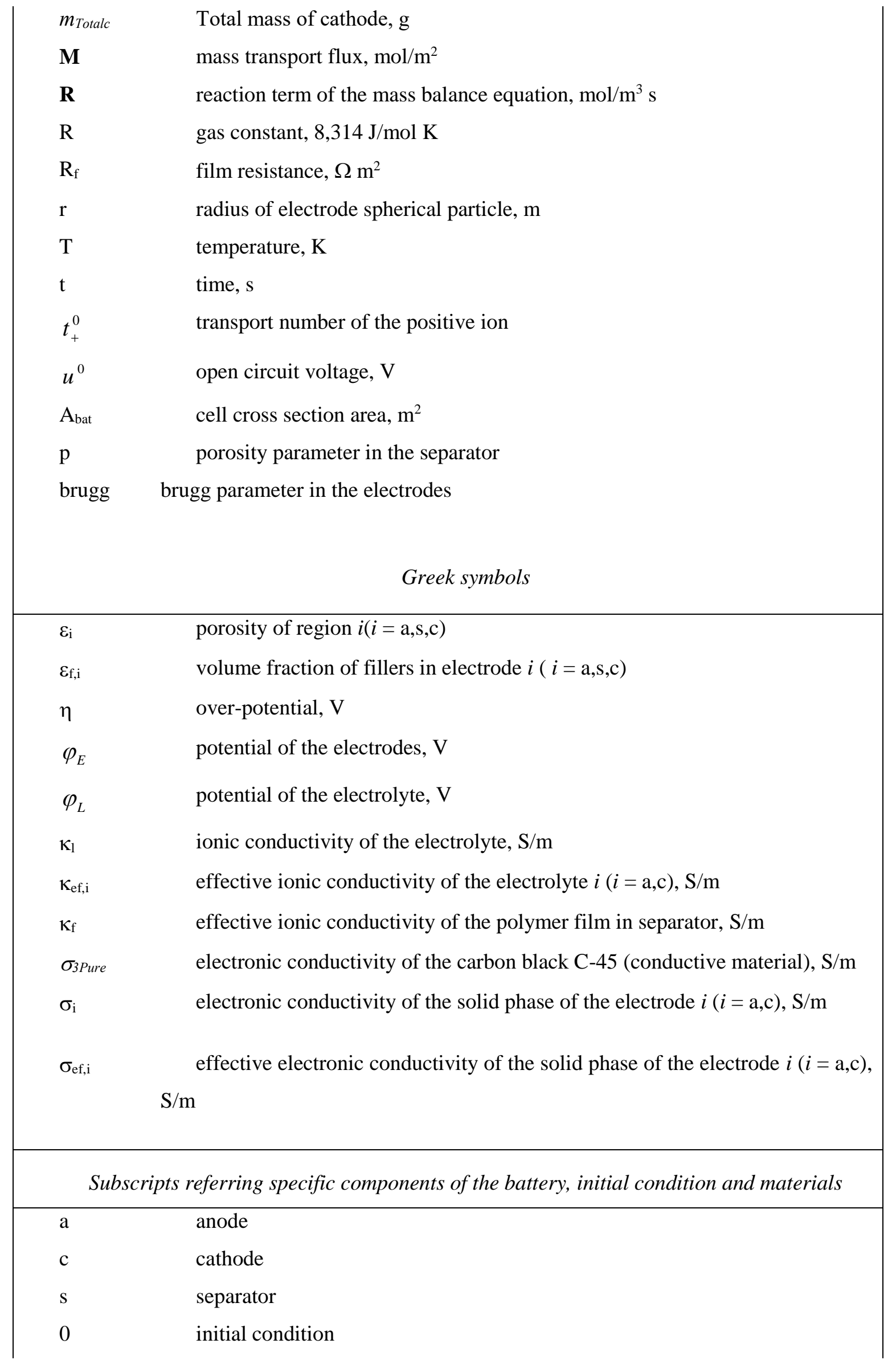


$1 \quad$ active material

2 binder

$3 \quad$ Carbon Black (C-45)

\section{References}

[1] E.C. Evarts, Lithium batteries: To the limits of lithium, Nature, 526 (2015) S93-S95.

[2] J.M. Tarascon, M. Armand, Issues and challenges facing rechargeable lithium batteries, Nature, 414 (2001) 359-367.

[3] C.A. Vincent, Lithium batteries: a 50-year perspective, 1959-2009, Solid State Ionics, 134 (2000) 159-167.

[4] M.S. Whittingham, Lithium Batteries and Cathode Materials, Chemical Reviews, 104 (2004) 4271-4302.

[5] C. Daniel, J.O. Besenhard, Handbook of Battery Materials, Wiley2012.

[6] M. Winter, R.J. Brodd, What Are Batteries, Fuel Cells, and Supercapacitors?, Chemical Reviews, 104 (2004) 4245-4270.

[7] M. Wakihara, O. Yamamoto, Lithium Ion Batteries: Fundamentals and Performance, Wiley2008.

[8] B. Scrosati, J. Garche, Lithium batteries: Status, prospects and future, Journal of Power Sources, 195 (2010) 2419-2430.

[9] J.W. Fergus, Recent developments in cathode materials for lithium ion batteries, Journal of Power Sources, 195 (2010) 939-954.

[10] J. Newman, Optimization of Porosity and Thickness of a Battery Electrode by Means of a Reaction-Zone Model, Journal of The Electrochemical Society, 142 (1995) 97-101.

[11] V. Ramadesigan, R.N. Methekar, F. Latinwo, R.D. Braatz, V.R. Subramanian, Optimal Porosity Distribution for Minimized Ohmic Drop across a Porous Electrode, Journal of The Electrochemical Society, 157 (2010) A1328-A1334.

[12] H. Zheng, R. Yang, G. Liu, X. Song, V.S. Battaglia, Cooperation between Active Material, Polymeric Binder and Conductive Carbon Additive in Lithium Ion Battery Cathode, The Journal of Physical Chemistry C, 116 (2012) 4875-4882.

[13] H. Zheng, L. Tan, G. Liu, X. Song, V.S. Battaglia, Calendering effects on the physical and electrochemical properties of $\mathrm{Li}[\mathrm{Ni} 1 / 3 \mathrm{Mn} 1 / 3 \mathrm{Co} 1 / 3] \mathrm{O} 2$ cathode, Journal of Power Sources, 208 (2012) 52-57. 
[14] A. Gören, C.M. Costa, M.M. Silva, S. Lanceros-Méndez, State of the art and open questions on cathode preparation based on carbon coated lithium iron phosphate, Composites Part B: Engineering, 83 (2015) 333-345.

[15] E. Martínez-Rosas, R. Vasquez-Medrano, A. Flores-Tlacuahuac, Modeling and simulation of lithium-ion batteries, Computers \& Chemical Engineering, 35 (2011) 1937-1948.

[16] Y.-H. Chen, C.-W. Wang, G. Liu, X.-Y. Song, V.S. Battaglia, A.M. Sastry, Selection of Conductive Additives in Li-Ion Battery Cathodes: A Numerical Study, Journal of The Electrochemical Society, 154 (2007) A978-A986.

[17] H. Kikukawa, K. Honkura, M. Koyama, Influence of inter-particle resistance between active materials on the discharge characteristics of the positive electrode of lithium ion batteries, Electrochimica Acta, 278 (2018) 385-395.

[18] G.F. Castelli, W. Dörfler, The numerical study of a microscale model for lithiumion batteries, Computers \& Mathematics with Applications, (2018).

[19] Z.Y. Jiang, Z.G. Qu, L. Zhou, Lattice Boltzmann simulation of ion and electron transport during the discharge process in a randomly reconstructed porous electrode of a lithium-ion battery, International Journal of Heat and Mass Transfer, 123 (2018) 500513.

[20] C. Sangrós Giménez, B. Finke, C. Nowak, C. Schilde, A. Kwade, Structural and mechanical characterization of lithium-ion battery electrodes via DEM simulations, Advanced Powder Technology, 29 (2018) 2312-2321.

[21] E. Hosseinzadeh, J. Marco, P. Jennings, The impact of multi-layered porosity distribution on the performance of a lithium ion battery, Applied Mathematical Modelling, 61 (2018) 107-123.

[22] R.E. Sousa, C.M. Costa, S. Lanceros-Méndez, Advances and Future Challenges in Printed Batteries, ChemSusChem, 8 (2015) 3539-3555.

[23] D. Miranda, C.M. Costa, S. Lanceros-Mendez, Lithium ion rechargeable batteries: State of the art and future needs of microscopic theoretical models and simulations, Journal of Electroanalytical Chemistry, 739 (2015) 97-110.

[24] P. Ram, A. Gören, S. Ferdov, M.M. Silva, R. Singha, C.M. Costa, R.K. Sharma, S. Lanceros-Méndez, Improved performance of rare earth doped LiMn2O4 cathodes for lithium-ion battery applications New Journal of Chemistry, 40 (2016) 6244-6252 
[25] S. Wang, L. Lu, X. Liu, A simulation on safety of $\mathrm{LiFePO} 4 / \mathrm{C}$ cell using electrochemical-thermal coupling model, Journal of Power Sources, 244 (2013) 101108.

[26] M. Safari, C. Delacourt, Modeling of a Commercial Graphite/LiFePO4 Cell, Journal of The Electrochemical Society, 158 (2011) A562-A571.

[27] S. Yu, S. Kim, T.Y. Kim, J.H. Nam, W.I. Cho, Model Prediction and Experiments for the Electrode Design Optimization of LiFePO4/Graphite Electrodes in High Capacity Lithium-ion Batteries, Bulletin of the Korean Chemical Society, 34 (2013) 9.

[28] M. Wang, J. Li, X. He, H. Wu, C. Wan, The effect of local current density on electrode design for lithium-ion batteries, Journal of Power Sources, 207 (2012) 127133.

[29] V. Srinivasan, J. Newman, Discharge Model for the Lithium Iron-Phosphate Electrode, Journal of The Electrochemical Society, 151 (2004) A1517-A1529.

[30] Y. Dai, L. Cai, R.E. White, Simulation and analysis of stress in a Li-ion battery with a blended LiMn2O4 and LiNi0.8Co0.15Al0.05O2 cathode, Journal of Power Sources, 247 (2014) 365-376.

[31] B. Lestriez, Functions of polymers in composite electrodes of lithium ion batteries, Comptes Rendus Chimie, 13 (2010) 1341-1350.

[32] R.J. Young, P.A. Lovell, Introduction to Polymers, Third Edition, Taylor \& Francis2011.

[33] J.W. Van Zee, E.S.I. Electrolysis, E.E. Division, E.S.E.T. Division, E.S. Meeting, Advances in Mathematical Modeling and Simulation of Electrochemical Processes and Oxygen Depolarized Cathodes and Activated Cathodes for Chlor-alkali and Chlorate Processes, Electrochemical Society 1998.

[34] C. Wang, J. Hong, Ionic/Electronic Conducting Characteristics of LiFePO4 Cathode Materials: The Determining Factors for High Rate Performance, Electrochemical and Solid-State Letters, 10 (2007) A65-A69.

[35] G. Ning, B. Haran, B.N. Popov, Capacity fade study of lithium-ion batteries cycled at high discharge rates, Journal of Power Sources, 117 (2003) 160-169.

[36] C. Glaize, S. Genies, Lithium Batteries and other Electrochemical Storage Systems, Wiley2013.

[37] Y. Shi, S.-L. Chou, J.-Z. Wang, D. Wexler, H.-J. Li, H.-K. Liu, Y. Wu, Graphene wrapped $\mathrm{LiFePO} 4 / \mathrm{C}$ composites as cathode materials for Li-ion batteries with enhanced rate capability, Journal of Materials Chemistry, 22 (2012) 16465-16470. 
